ZOOLOGIA 29 (6): 598-600, December, 2012

Available online at www.scielo.br/zool

\title{
A new species of Ischnura (Odonata: Coenagrionidae) from high altitude eastern Andes, of Colombia
}

\author{
Angelo B. M. Machado \\ Departamento de Zoologia, Instituto de Ciências Biológicas, Universidade Federal de Minas Gerais. Caixa Postal 486, \\ 31270-901 Belo Horizonte, Minas Gerais, Brasil. E-mail: angelo@icb.ufmg.br

\begin{abstract}
Ischnura mahechai sp. nov. is described and illustrated based on specimens collected at the Eastern Andean mountain range of Colômbia. The species is close to Ischnura cruzi De Marmels, 1987 but differs from it by the structure of male anal appendages and female hind prothoracic lobe. The specimens were collected on a small Andine lake at $3,600 \mathrm{~m}$, the $4^{\text {th }}$ altitudinal record for a resident odonate.
\end{abstract} \\ KEY WORDS. Andes; altitudinal record; damselflies.
}

Ischnura is a cosmopolitan genus of damselflies with 65 species, out of which 20 are recorded in the New World and distributed from Canada to central Chile and Argentina (GARRISON et al. 2010). The Colombian fauna has eight species (PerezGutierrez \& Palacino-Rodriguez 2011) five of which inhabiting in the high altitude mountains of the Eastern Andes near Bogota, namely I. capreolus (Hagen, 1861), I. chingaza Realpe, 2010; I. cruzi De Marmels, 1987, I. cyane Realpe, 2010 \& I. ramburii (Selys, 1850). We describe herein a new species from the same region, collected at an elevation of 3,600 m.

\section{MATERIAL AND METHODS}

The type specimens are in collection A.B.M. Machado, deposited in the Taxonomic Collections of the Universidade Federal de Minas Gerais, UFMG, registered as I.OD-2012-0058 (holotype) and I-OD-0059 (allotype). Venation system according to Tillyard \& Fraser (1938). Abbreviations: S1-S10, abdominal segments 1 to 10; FW, forewings; HW, hindwings; PX, postnodals.

\section{TAXONOMY}

\section{Ischnura mahechai sp nov.}

Figs 1-9

Description. Holotype male. Head: missing Prothorax black except for a distolateral pilose projection of median lobe that is whitish green. Pterothorax: mesopleurum black with a narrow antehumeral stripe whitish green, metapleurum whitish green with a dark brown stripe on the metepisternun and a black line at the second lateral suture. In all legs extensor parts of femora and tibiae black, flexural parts yellowish, tarsi yellowish. Wings hyaline, FW pterostigma dark brown (Fig. 1). HW pterostigma light brown (Fig. 2), surrounded by yellow, smaller than that of FW. PX in FW 8-9, in HW 7-8; R3 arising in FW near PX4 in HW near PX3. Abdomen S1-S10 dorsally black, ventrolateraly yellowish blue with narrow bluish yellow incomplete basal rings.

Structural characters: hind prothoracic lobe straight with median lobe poorly developed. Penis with distal segment deeply bifid (Figs 7 and 8) forming two long curved processes. Second segment with a pair of posteriorly directed strongly curved spine proximal to flexure, not overpassing the lateral border of the segment. Hind border of S10 with a robust projection directed dorsoposteriorly (Fig. 5) with the apex bifid (Fig. 6). Cercus directed posteriorly (Fig. 5) tapering into a sclerotized tip provided with a medially directed tooth (Fig. 6), a with a slightly curved decumbent process at about midlength (Fig. 5). Paraproct in lateral view (Fig. 5) subtriangular with a distal spine, $1 / 3$ shorter than $\mathrm{S} 10$.

Measurements (mm) HW 13.6, Abdomen 20.0. Cercus 3.1 .

Allotype female. Head: labium whitish yellow, face olive with a black line on the frontoclypeal suture. Upper part of head black with olive black rounded poorly defined postocular spots. Postocular area and occipital ridge brown. Prothorax black. Pterothorax, mesepisternum black with a midcentral narrow yellow stripe. Mesepimerum olive, metapleurum black. Legs: femora dorsally black, ventrally olive. Tibiae and tarsi yellow. Wings hyaline, pterostigma in both wings yellow, slightly smaller in HW, (Figs 1 and 2). PX in FW 9-10 in HW 7.8. R3 arising near PX4 in FW and near PX3 in HW. Abdomen ventrally olive yellow, dorsally black with slightly pruinose areas on S1-S6. Cerci brownish red.

Structural characters: hind prothoracic lobe (Fig. 9) with medial and lateral lobes well developed, the latter with crenulated border. No ventral spine on S8. Cerci digitiform.

Measurements (mm) HW 15.3, abdomen: 19.0. 

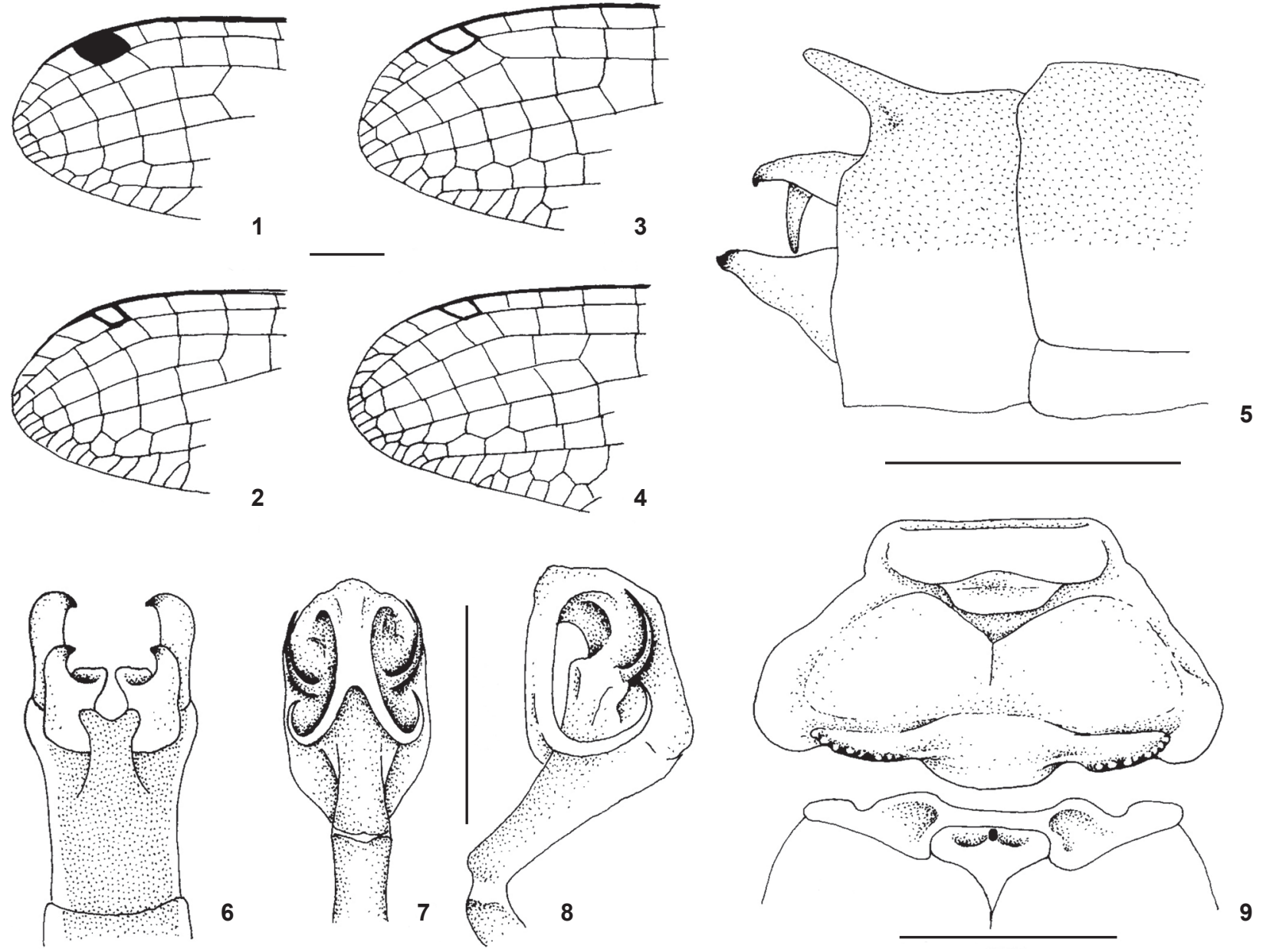

Figures 1-9. Ischnura mahechai sp. nov.: (1-2) holotype male: (1) forewings; (2) hindwings; (3-4) female allotype: (3) forewings ; (4) hindwings; (5-7) male holotype abdominal segments: abdominal segments 1 to 10 in lateral (5) and dorsal (6) views; penis in dorsal (7) and lateral (8) views; (9) female allotype, phothorax and mesostigmal plates in dorsal view. Scale bars: $1-4=1.0 \mathrm{~mm}, 5=5.0 \mathrm{~mm}$, $6-8=0.5 \mathrm{~mm}, 9=1.0 \mathrm{~mm}$.

Type material. Holotype male and allotype female, CoLOMBIA, Department of Cundinamarca: municipality of Guatavita, ( $\left.4^{\circ} 55^{\prime} 50^{\prime \prime} \mathrm{S}, 73^{\circ} 49^{\prime} 59^{\prime \prime} \mathrm{W}, 3,600 \mathrm{~m}\right)$. Handpicked on a small shallow lake situated at about $5 \mathrm{~km}$ east of Guatavita, 16-XI-1989 (paramo vegetation), G.A.B. Mahecha leg.

Etymology. Named mahechai, in honor of my good friend Prof. Germán Arturo Bohorquez Mahecha who collected the type specimens in Colombia.

Remarks. By the morphology of $\mathrm{S} 10$ and appendages $I$. mahechai sp. nov. is much different from the 15 North and Central America Ischnura redescribed and illustrated by WESTFALL \& May (2006). In the key of Heckman (2008) for South American species if keys out to I. ultima Ris, 1908 but differs from it by having the abdomen totally black in both sexes (with blue markings in I. ultima); the male projection of S10 directed dorsoposteriorly (Fig. 5) (dorsally in I. ultima) and the decumbent process only slightly curved (strongly curved in I. ultima). I. mahechai sp. nov. fits none of the species in REALPE's key for the Ischnura of Colombian Eastern Cordillera. Taking in consideration the appendages $I$. mahechai sp. nov. is closer to $I$. cruzi, sharing with it the decumbent process originating at about midlength of cercus. It differs however from it by having the paraprocts $1 / 3$ shorter than $S 10$ (subequal in $I$. cruzi), in lateral view subtriangular (subcylindrical in $I$. cruzi), the internal spine of penis segment 2 strongly curved and not overpassing the border (Figs 7 and 8) (slightly curved and overpassing the border in I. cruzi). Besides, in I. mahechai sp. nov. the abdomen is totally black (In I. cruzi S1, S2, dominantly yellow, S8 pale blue, S9 anteriorly pale blue). The female of I. mahechai sp. nov. has the border of the lateral lobes of the hind prothorax lobe crenu- 
lated (smooth in I. cruzi). REALPE (2010) studied the occurrence of Ischnura across a vertical gradient in the high mountains of Eastern Andean Cordillera near Bogota. At lower altitudes (1,300 $\mathrm{m}$ and 2,000 m) I. cyane shared habitat with $I$. capreolus and $I$. ramburi; at 2,600 $\mathrm{m} \mathrm{I}$. cruzi and I. chingaza occurred and at higher altitudes $(3,200 \mathrm{~m})$ only I. chingaza was found. I. mahechai sp. nov. that occurs in the same mountain region, was found at $3,600 \mathrm{~m}$ altitude that is $1,000 \mathrm{~m}$ above its closer species $I$. cruzi. According to the collector Prof. Germán A.B. Mahecha, the species was extremely abundant on the margin of the small lake where the two type specimens have been collected. This fact indicates that it was resident there and not simply carried by air currents. The record of I. mahechai sp. nov. at 3,600 m is the fourth highest record registered for resident odonata being overpassed only by Neallogaster latifrons Selys, 1878 in Nepal $(4,505 \mathrm{~m})$, Protallagma titicacae (Calvert, 1908) $(4,720 \mathrm{~m})$ and Rhionaeschna peralta (Ris, 1918) at 5,050 $\mathrm{m}$ both in the Peruvian Andes (CORbet 2004).

\section{ACKNOWLEDGEMENT}

We are grateful to Emilio Realpe for donation of specimens of Ischnura for comparative purposes and to the biologist
Myrian Morato Duarte for the drawings illustrating this paper.

\section{LITERATURE CITED}

Corbet, P.S. 2004. Dragonflies: behavior and ecology of Odonata. Ithaca, Cornell University Press, 829p.

Garrison, R.G.; N. von ElLENRIEDER \& J.A. Louton. 2010. Damselfly genera of the New World. Baltimore, Johns Hopkins University Press, 490p.

Heckman, C.W. 2008. Encyclopedia of South American Aquatic Insects: Odonata-Zygoptera. Dordrecht, Springer, vol. 5, 689p.

Perez-Gutierrez, L.A. \& F. Palacino-Rodriguez. 2011. Updated checklist of the Odonata known from Colombia. Odonatologica 40 (3): 203-225.

ReAlPE, E. 2010. Two new Andean species of the genus Ischnura charpentier from Colombia, with a key to the regional species (Zygoptera: Coenagrionidae). Odonatologica 39 (2): 121-131.

Tillyard, R.J. \& F.C. Fraser, 1938. A reclassification of the order Odonata based on some new interpretations of the venation of the dragonfly wing. Australian Zoologist 9: 125-169.

Westfall, M.J. \& M.L. May. 2006. Damselflies of North America. Gainesville, Scientific Publishers, 502p.

Submitted: 04.X.2012; Accepted: 16.XI.2012.

Editorial responsibility: Sionei R. Bonatto

ZOOLOGIA 29 (6): 598-600, December, 2012 